Uluslararası Mühendislik

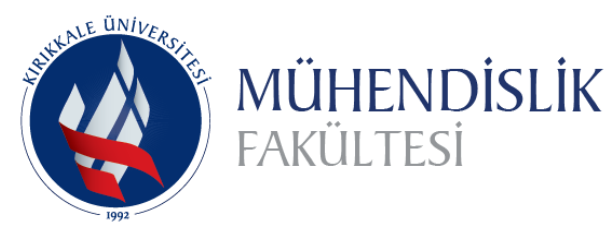

Araștırma ve Geliștirme Dergisi UMAGD, (2022) 14(1), 262-270.

International Journal of

Engineering Research and

Development

Cilt/Volume:14 Sayı/Issue:1 Ocak/January 2022

Araştırma Makalesi / Research Article

\title{
Alümina Porselen Bünyelerde Spodumen İlavesinin Teknik Özelliklere Etkisinin Araştırılması
}

\section{Investigation of the Effect of Spodumene Addition on Technical Properties in Alumina Porcelain Bodies}

\author{
Baran Tarhan iD, Müge Tarhan \\ Usak University, Güzel Sanatlar Fakültesi, Seramik Bölümü, 64000 ve Uşak, TÜRKIYYE
}

Başvuru/Received: 15/12/2021

Kabul / Accepted: 10/01/2022

Çevrimiçi Basım / Published Online: 15/01/2022

Son Versiyon/Final Version: 15/01/2022

\section{$\ddot{O} \mathbf{z}$}

Porselen bünyeler sahip oldukları üstün teknik özellikleri nedeni ile pek çok alanda tercih edilen seramik ürünler arasında yer almaktadır. Çoğunlukla en az $1200^{\circ} \mathrm{C}$ ve üzerindeki sıcaklıklarda pişirilen porselen bünyelerin pişirim süreleri ürün tasarımı, boyutu ve bünye kompozisyon tasarımına bağlı olarak değişmektedir. Yüksek alüminalı porselen bünyelerin sinterleme sıcaklıklarının düşürülmesinin enerji maliyetleri ve verimlilik açısından önemi büyüktür. Çalışmada yüksek alüminalı porselen bünyelerde spodumen kullanımı araştırılmıştır. Standart yüksek alüminalı porselen bünye reçetesine kademeli spodumen ilave edilerek yeni bünye reçeteleri oluşturulmuştur. Hazırlanan porselen çamurların reolojik özellikleri ölçülmüş, pişirilen bünyelerin fiziksel ve isıl özellikleri incelenmiştir. Bünyelerin ısıl genleşme katsayıları dilatometre cihazı ile belirlenmiştir. Sinterleme sürecinde bünyelerde gelişen fazlar X-1şınları difraktometresi ile belirlenmiş, mikroyapıları taramalı elektron mikroskobu ile incelenmiş̧ir. Sonuçlara göre yüksek alüminalı porselen bünyede spodumen kullanımı çamurun reolojik özelliklerini değiştirmezken bünyelerin sinterlenme davranışı gelişmiş, bünyelerin su emmesi düşmüş ve pişme küçülmesi artmıştır. Bununla birlikte bünyelerin mekanik davranışlarında da belirgin iyileşme tespit edilmiştir. Ancak spodumen kullanımı bünyelerin deformasyonunda önemli bir artışa neden olmuştur. Sonuç olarak yüksek alüminalı porselen bünyelerde spodumen kullanımı ile bünyelerin teknik özellik ve mikroyapılarının kontrolü ile pişirim koşullarında pişirim sıcaklık ve süresinin azaltılması yönünde optimizasyonların yapılabileceğini göstermektedir.

\section{Anahtar Kelimeler}

"Alümina porselen, spodumen, sinterleme"

\begin{abstract}
Porcelain bodies are among the preferred ceramic products in many fields due to their superior technical properties. The firing times of porcelain bodies, which are mostly fired at temperatures of at least $1200^{\circ} \mathrm{C}$ and above, vary depending on the product design, size and body composition design. Reducing the sintering temperatures of high alumina porcelain bodies is of great importance in terms of energy costs and efficiency. In the study, the use of spodumene in high alumina porcelain bodies was investigated. New body recipes were prepared by adding gradual spodumene to the standard high alumina porcelain body recipe. The rheological properties of the prepared porcelain bodies were measured, and the physical and thermal properties of the fired bodies were examined. The thermal expansion coefficients of the structures were determined by the dilatometer. The phases developed in the bodies during the sintering process were determined by X-ray diffractometry, and their microstructures were examined by scanning electron microscope. According to the results, while the use of spodumene in the high alumina porcelain body did not change the rheological properties of the slip, the sintering behavior of the bodies improved, the water absorption of the bodies decreased and the firing shrinkage increased. In addition, a significant improvement in the mechanical behavior of the bodies was also detected. However, the use of spodumene caused a increase in the deformation of the bodies. As a result, it shows that optimizations can be made in order to reduce the firing temperature and time in firing conditions by using spodumene in high alumina porcelain bodies and by controlling the technical properties and microstructures of the bodies.
\end{abstract}

Key Words

"Alumina porcelain, spodumene, sintering"

*Sorumlu Yazar: baran.tarhan @usak.edu.tr 


\section{Giriş}

Sağlık gereçleri, elektriksel yalıtkanlar, diş protezleri ve sofra ve dekoratif süs eşyaları gibi pek çok alanda kullanılmakta olan porselenler beyaz pişen, düşük su emme özelliğine sahip ve camsı (vitrifiye) yapıya sahip seramik malzemeler olarak tanımlanmaktadır. Hammaddeler, üretim aşamaları ve pişirim sürecinin kinetikleri arasındaki karşılıklı etkileşimlerden dolayı porselenler seramik sistemler içerisindeki belki de en karmaşık sistemlerdir. Bu karmaşık reaksiyonlar nedeniyle porselenlerin yoğunluk, porozite, su emme, mukavemet, deformasyon, renk ve şeffaflık gibi teknik özelliklerini elde edilen mikroyapı kontrol eder. Vitrifikasyon yüksek pişirim sicaklıklarında yüksek derecede ergimenin gerçekleşmesidir. Bunun sonucu olarak porselen bünyeler düşük porozite $(<\% 0,5)$ ve yüksek camsı faza (>\%40) sahiptir. Porselenlerin mikroyapısı ağırlıklı olarak müllit kristalleri, kristal kuvars, camsı faz, ve nadiren artık feldispat ve poroziteden oluşur. Porselenler genellikle $\% 50$ kil $/$ kaolen, $\% 25$ ergitici ve $\% 25$ dolgu hammaddelerinden oluşan üç eksenli bir formülasyona sahiptir. Kil diğer hammaddeler arasında bağlayıcı görevi görerek bünyenin şekillendirilmesi için yeterli plastikliği sağlar ve genellikle kaolenler tercih edilir. Ergiticiler diğer bileşenlerle reaksiyona girerek sistemde camsı faz oluşum sıcaklığını düşürürler. Pişirim sürecinde gelişen bu camsı faz mikroyapıda yoğunlaşmayı sağlar. Ergitici olarak kullanılan hammaddeler sodyum feldispat, potasyum feldispat ve nefelin siyenit gibi alkali feldispatlardır. Dolgu hammaddesi olarak çoğunlukla kullanılan kuvars pişirim sıcaklıklarında kararlı bir pişirim sağlarken, yapısal bozulmayı ve küçülmeyi önler. Ayrıca kalsine alümina kuvars dönüşümünün etkisini azaltmak ve bünyenin mekanik özelliklerini geliştirmek için kuvars yerine dolgu maddesi olarak kullanılmaktadır. Alüminanın feldispatik camsı faz içerisindeki çözünürlüğü kuvarsla kıyaslandığında oldukça yavaştır (Carty ve Senapati 1998, Lee ve Iqbal 2001, Turkmen ve ark. 2015, Lerdprom ve ark. 2016, Güngör ve Ay 2018). Bunların yanı sıra CaO kaynağ1 olarak vollastonit ve anortit de porselen üretiminde kullanılabilir. Vollastonit yaklaşık $1450^{\circ} \mathrm{C}$ 'de ergimeye başlar ve alkali feldispatlar gibi ergitici olarak kabul edilmez. Bu diğer bileşenlerle olan reaksiyonuna bağlıdır. Hızlı 1sıtma ve soğutma çevriminde çatlama ve yapısal bozulma olmadan pişirim sürecinin tamamlanması için vollastonit kullanımı önemlidir. Üçlü porselen sistemlerine vollastonit ilavesi pişirim sıcaklığını düşürebilir ve bünyenin mukavemetini artırabilir. Anortit beyaz pişen porselen bünyeler için kullanılabilecek bir diğer mineraldir (Güngör 2018, Turkmen ve ark. 2015, Ke ve ark. 2013, Kurama ve Ozel 2009). Kurama ve Özel yaptıkları çalışmada anortit oluşmunun kullanılan $\mathrm{CaO}$ kaynağında çok pişirim sıcaklığına bağlı olduğunu belirtmişlerdir. Mikroyapıda anortit kristalizasyonu, albitten anortit yapısına geçişteki kristallografik yapı değişimi nedeni ile bünyenin yoğunluğunu, mukavemetini ve kimyasal kararlılı̆̆ını artırır (Kurama ve Ozel 2009).

Porselenlerin üretimi sırasında en büyük enerji tüketimi pişirime işlemi sırasında meydana gelmektedir. Bu nedenle pişirim rejimini ve kimyasal kompozisyonu değiştirerek toplam enerji tüketimini azaltmaya yönelik pek çok çalışma yapılmıştır (Kivitz ve ark. 2009, Bragança ve ark. 2011, Bragança ve ark. 2012, Carús ve ark. 2012, Kunduracı ve Aydın 2015, Brasileiro ve ark. 2021, Tarhan ve Tarhan 2021). Esposito ve ark. yaptıkları çalışmada nefelin siyenitin porselen karo bünyelerinde pişirim sıcaklığını düşürerek enerji tasarrufu sağladığını belirtmişlerdir. Alkali içeriği yüksek olan nefelin siyenit porselen bünyenin daha iyi sinterlenmesini sağlayarak, açık poroziteyi ve dolayısıyla bünyenin su emmesini düşürürken, mukavemetini arttırmaktadır (Ceylan ve ark 2005, Esposito ve ark. 2005, Kunduracı ve Aydın 2015, Elmaghraby ve ark. 2020). Porselen karo ve sağlık gereçleri bünyelerinde bir $\mathrm{Li}_{2} \mathrm{O}$ kaynağı olarak spodumenin kullanımı üzerine yapılan çalışmalarda, spodumenin camsı faz oluşum sıcaklığını ve viskozitesini düşürerek bünyelerin sinterleme performansını geliştirdiği tespit edilmiştir. Spodumen ilavesi ile düşük viskozitedeki camsı faz taneler arası boşlukları daha kolay doldurarak poroziteyi ve por boyutunu düşürür. Ayrıca düşük viskozitedeki camsı faz ikincil müllit kristallerinin gelişimini de destekleyerek mekanik karakteristikleri de geliştirir (Iqbal ve Lee 1999, Iqbal ve ark. 2000, Lu ve ark. 2004, Tucci ve ark. 2007).

$\mathrm{Bu}$ çalışmada yüksek alüminalı porselen bünyelerde $\mathrm{Li}_{2} \mathrm{O}$ kaynağı olarak spodumenin kullanımı ve bünye teknik özelliklerine etkileri incelenmiş̧ir. Çalışmada; standart yüksek alüminalı bünye reçetesine kademeli olarak spodumen ilave edilmiş̧ir. Bu şekilde geliştirilen bünyelerin fiziksel ve 1 sıl özellikleri incelenerek spodumenin yüksek alüminalı porselen karo bünyelerde kullanılabilirliği araştırılmıştır.

\section{Materyal ve Yöntem \\ 2.1.Bünye geliştirme çalışmaları}

Yüksek alüminalı bünye çalışmalarında üç farklı tür kaolen, kil, kuvars, potasyum feldispat ve $\operatorname{Li}_{2} \mathrm{O}$ kaynăg 1 olarak spodumen kullanılmıştır. Hammaddelerin XRF ile tayin edilmiş ait kimyasal analiz sonuçları Tablo 1'de verilmiştir. Reçetelerde kullanılan Kaolen 1 ve Kaolen 2 hammaddeleri Sibelco-Birleşik Krallık, Kil ve Potasyum feldispat hammaddeleri Kalemaden A.Ş-Türkiye, Kaolen 3 hammaddesi Kaolin Endüstriyel Mineraller San. ve Tic. A.Ş.-Bulgaristan, Kuvars ve spodumen Esan Eczacıbaşı Endüstriyel Hammaddeler San. ve Tic. A.Ş. Türkiye’den temin edilmiştir. 
Tablo 1. Hammaddelerin XRF ile tayin edilmiş kimyasal bileşimleri (\% ağ.)

\begin{tabular}{lrrrrrrrrrr}
\hline & $\mathbf{A . Z}$ & $\mathbf{S i O}_{2}$ & $\mathbf{A l}_{2} \mathbf{O}_{3}$ & $\mathbf{T i O}_{2}$ & $\mathbf{F e}_{2} \mathbf{O}_{3}$ & $\mathbf{C a O}$ & $\mathbf{M g O}$ & $\mathbf{N a}_{2} \mathbf{O}$ & $\mathbf{K}_{2} \mathbf{O}$ & $\mathbf{L i}_{2} \mathbf{O}$ \\
\hline Kil & 9,24 & 56,51 & 27,25 & 2,24 & 1,26 & 0,38 & 0,68 & 0,1 & 2,34 & 0 \\
Alümina & 0,20 & 0 & 99,55 & 0 & 0 & 0 & 0 & 0,25 & 0 & 0 \\
Kaolen 1 & 11,3 & 48,88 & 35,65 & 0,89 & 0,14 & 0,05 & 0,35 & 0,03 & 2,71 & 0 \\
Kaolen 2 & 10,03 & 57,77 & 26,96 & 0,94 & 1,42 & 0,17 & 0,36 & 0,29 & 2,06 & 0 \\
Kaolen 3 & 11,94 & 51,38 & 34,22 & 0,95 & 0,36 & 0,15 & 0,16 & 0,11 & 0,73 & 0 \\
Kuvars & 0,21 & 98,15 & 1,08 & 0,03 & 0,02 & 0 & 0,05 & 0,34 & 0,12 & 0 \\
Potasyum Feldispat & 0,22 & 68,13 & 17,87 & 0,06 & 0,02 & 0,24 & 0,11 & 3,21 & 10,14 & 0 \\
Spodumen & 0,28 & 67,86 & 24,89 & 0,08 & 0,01 & 0,53 & 0,16 & 0,47 & 0,24 & 5,48 \\
\hline
\end{tabular}

Yüksek alüminalı standart porselen bünye reçetesi 3 farklı tür kaolen, kil, kuvars, K-feldispat ve alümina hammaddelerinden oluşmaktadır. spodumenin yüksel alüminalı porselen bünye üzerine olan etkilerini belirlemek için yapılan çalışmada \% 2, 5, 10 oranlarında spodumen standart reçete üzerine ilave edilmiştir. Oluşturulan reçeteler sırasıyla SP2, SP5 ve SP10 olarak kodlanmıştır. Standart bünye ve spodumen ilavesi ile geliştirilen bünye reçetelerinin oksit oranları Tablo 2'de verilmiştir.

Tablo 2. Standart ve geliştirilen bünyelere ait oksit kompozisyonları (\%)

\begin{tabular}{lllllllllll}
\hline & $\mathbf{A . Z}$ & $\mathbf{S i O}_{2}$ & $\mathbf{A l}_{2} \mathbf{O}_{3}$ & $\mathbf{T i O}_{2}$ & $\mathbf{F e}_{2} \mathbf{O}_{3}$ & $\mathbf{C a O}$ & $\mathbf{M g O}$ & $\mathbf{N a}_{2} \mathbf{O}$ & $\mathbf{K}_{2} \mathbf{O}$ & $\mathbf{L i}_{2} \mathbf{O}$ \\
\hline STD & 5,14 & 49,33 & 40,29 & 0,71 & 0,41 & 0,16 & 0,23 & 0,79 & 2,95 & 0,00 \\
SP2 & 5,05 & 49,69 & 39,99 & 0,70 & 0,40 & 0,16 & 0,23 & 0,78 & 2,89 & 0,11 \\
SP5 & 4,91 & 50,21 & 39,56 & 0,68 & 0,39 & 0,17 & 0,23 & 0,77 & 2,82 & 0,26 \\
SP10 & 4,70 & 51,01 & 38,89 & 0,65 & 0,37 & 0,19 & 0,23 & 0,76 & 2,70 & 0,50 \\
\hline
\end{tabular}

Yüksek alüminalı porselen bünye çalışmalarında bazı hammaddeler $63 \mu \mathrm{m}$ altında alınarak, bazıları ise ögütülerek $63 \mu \mathrm{m}$ altına düşürülerek kullanılmıştır. Hammaddelerin bünye reçetelerindeki kullanım oranları \% rutubet değerleri de hesaplanarak oluşturulmuştur. Reçete oranlarına göre tartılan hammaddeler elektrolit ve su ilaveleri ile laboratuvar tipi hızlı karıştırıcıda katı konsantrasyonları \%72, yoğunluk değeri yaklaşık $1870 \mathrm{~g} / \mathrm{lt}$ olacak şekilde ayarlanmıştır. Hazırlanan çamurların reolojik değerleri Gallenkamp viskozimetresi ile ölçülmüştür. Çamur viskoziteleri $315-325^{\circ}\left(\mathrm{V}_{\mathrm{o}}\right), 300-310^{\circ} 1$. dakika viskoziteleri $\left(\mathrm{V}_{1}\right)$ ve $240-260^{\circ} 6$. dakika viskoziteleri $\left(\mathrm{V}_{6}\right)$ olacak şekilde ayarlanmıştır. Hazırlanan çamurlar 1 gün dinlendirildikten sonra $190 \times 25 \times 15 \mathrm{~mm}$ döküm boşluğuna sahip alçı kalıp kullanılmıştır. Şekillendirme işleminden sonra 24 saat oda sıcaklığında bekletilen numuneler $110^{\circ} \mathrm{C}^{\prime}$ lik etüvde 24 saat süre ile kurutulmuştur. Numunelerin pişirimleri $1225^{\circ} \mathrm{C}$ 'de 14 saat süre ile endüstriyel tünel firında gerçekleştirilmiştir.

\subsection{Karakterizasyon}

Bünye çalışmalarında kullanılan hammaddelerin kimyasal analizleri X- ışını floresans spektometresi (XRF) ile tespit edilmiştir. Bünyelerin fiziksel özellikleri (su emme, kuru-pişme küçülmesi, mukavemet vb.) TS EN 997 standardına göre yapılmış, test sonuçlarında yapılan 5 ölçümün ortalama değeri alınmış ve $\% \pm 1,5$ standart sapma değeri olacak şekilde değerlendirme yapılmıştır. Numunelerin kuru-pişme mukavemetleri üç noktalı eğme testi ile belirlenmiştir. Bünyelerin pişme deformasyonu iki destek arasına yerleştirilen deformasyon çubuklarında sıcaklıkla meydana gelen değişimin milimetre cinsinden ölçülmesi yöntemi ile belirlenmiştir. Pişme deformasyonu tespiti için her bünyenin $1 \times 4 \times 26 \mathrm{~cm}$ boyutlarında deformasyon çubukları döküm yöntemi ile hazırlanmıştır. $1200^{\circ} \mathrm{C}$ tepe sıcaklığında deformasyon çubuklarında meydana gelen eğilme milimetre cinsinden ölçülerek deformasyon değerleri belirlenmiştir. Aynı sıcaklık değeri için numunelerin su emme değerleri de hesaplanmış deformasyon analizleri ile karşılaştırılarak numunelerin sinterleme davranışları belirlenmiştir. Numunelerin 1sıl genleşme katsayısı tespiti dilatometre cihazı ile yapılmıştır. Bünyelerde gelişen fazlar X- ışınları difraktometresi, CuKa, $40 \mathrm{kV}$ ve $30 \mathrm{~mA}$ şartlarında $10^{\circ}-70^{\circ}$ aralı̆̆ında, tarama hızı $2^{\circ} / \mathrm{dak}$. şartlarında belirlenmiştir.

\section{Bulgular ve Tartışma}

\subsection{Bünye Çamurlarının teknik özellikleri}

Yüksek alüminalı porselen bünyelerin kimyasal kompozisyonları Tablo 2'de verilmiştir. Bünye kompozisyonlarında $\mathrm{Li}_{2} \mathrm{O}$ kaynağı olarak spodumen kullanılmasıyla birlikte $\mathrm{Na}_{2} \mathrm{O}$ ve $\mathrm{K}_{2} \mathrm{O}$ oranları düşmekte, toplam alkali miktarı belirgin şekilde değişmezken $\mathrm{SiO}_{2}$ miktarı ise spodumen kaynağındaki $\mathrm{SiO}_{2}$ miktarının kil ve kaolen gibi hammaddelere göre fazla olması nedeniyle birlikte artmaktadır. 
Bünye çamurlarına ait yoğunluk ve akışkanlık değerleri Tablo 3'te verilmiştir. Çamurların ilk $\left(\mathrm{V}_{0}\right)$, 1. dakika $\left(\mathrm{V}_{1}\right)$ ve 6. dakikada $\left(\mathrm{V}_{6}\right)$ ölçülen viskoziteleri incelendiğinde yüksek alüminalı porselen bünyelerde spodumen kullanımı ile birlikte akışkanlık değerlerinin belirgin şekilde değişmediği tespit edilmiştir. Bünyelerin kalıllık alma değerleri incelendiğinde tüm bünyelerde kalınlık alma değerlerinin birbirlerine yakın ve $8,0-8,5 \mathrm{~mm} / 90$ dakika aralığında olduğu görülmektedir. Bünye çamurlarının tüm reolojik özellikleri incelendiğinde yüksek alüminalı porselen bünyelerinde spodumen kullanımının çamur reolojik özellikleri üzerine belirgin bir etkisi olmadığ tespit edilmiştir.

Yüksek alüminalı porselen bünyelerde kil ve 3 farklı tür kaolen kullanılmıştır. Kil özlü hammaddelerden olup bünyeye plastik özellik kazandırmak için kullanılmakta, ürüne yaş ve kuru dayanım sağlarken aynı zamanda şekillendirme sonrası uygulanan rötuş işlemlerini de mümkün kılmaktadır. Kaolenler ise döküm yöntemi ile şekillendirme yönteminde çamurun kalınlık alma özelliğini kontrol eder. Bu nedenle farklı özelliklerde kaolenlerin kullanılması ile bünyelerin kalınlık alma süreleri kontrol edilmektedir. Alkali kaynağı olarak kullanılan potasyum feldispat bünyede ergitici görevini üstlenirken, alümina bünyeye yüksek mukavemet kazandırmak için kullanılmaktadır. Çalışmada yüksek alüminalı porselen bünyelerde spodumen kullanımının çamurun akışkanlık ve kalınlık alma özelliklerinde belirgin farklar yaratmadığı, teknik özelliklerin standart bünye değerlerine yakın olarak elde edildiği tespit edilmiştir.

Tablo 3. Vitrifiye bünye çamurlarının teknik özellikleri

\begin{tabular}{|c|c|c|c|c|}
\hline & STD & SP2 & SP5 & SP10 \\
\hline Yoğunluk (g/lt) & 1875 & 1874 & 1870 & 1872 \\
\hline Viskozite ( $V_{o}$ - Gallenkamp $\left.\mathbf{G}^{0}\right)$ & 65 & 70 & 75 & 70 \\
\hline 1. dak. Viskozite ( $V_{1}$ - Gallenkamp $\left.G^{0}\right)$ & 325 & 315 & 315 & 324 \\
\hline 6. dak. Viskozite ( $\mathrm{V}_{6}$ - Gallenkamp $\left.\mathrm{G}^{0}\right)$ & 260 & 245 & 240 & 254 \\
\hline Elektrolit (\%) & 0,35 & 0,38 & 0,40 & 0,41 \\
\hline Kalınlık Alma (mm - 60 dak.) & 8,2 & 8,3 & 8,5 & 8,5 \\
\hline
\end{tabular}

\subsection{Fiziksel Özellikler}

Spodumen ilavesi ile geliştirilen bünyelerin fiziksel özellikleri Tablo 4'te verilmiştir. Bünyelerde kullanılan spodumen ilavesi ve spodumen oranındaki artış ile birlikte su emme değerlerinde belirgin bir azalma, pişme küçülme değerlerinde ise artış tespit edilmiştir. $\mathrm{Bu}$ da yüksek alüminalı porselen bünyelerde spodumen kullanımının bünye sinterlenmesini arttırdığını göstermektedir. Bünyelerde spodumen kullanılması kompozisyonlarda $\mathrm{Li}_{2} \mathrm{O}$ ve toplam alkali oksit oranını artırırken diğer alkali oksit $\left(\mathrm{Na}_{2} \mathrm{O}, \mathrm{K}_{2} \mathrm{O}\right)$ oranlarında ve $\mathrm{Al}_{2} \mathrm{O}_{3}$ oranında azalmaya neden olmaktadır.

Porselen bünyelerde ekonomik ve uygun pişirim sıcaklığı için genellikle $\mathrm{SiO}_{2}-\mathrm{Al}_{2} \mathrm{O}_{3}-\mathrm{M}_{2} \mathrm{O}$ üçlü sistemine bağlı olan kompozisyonlar kullanılmaktadır. Pişirim sürecinde camsı fazın gelişimi porselen bünyelerin sinterlenerek yoğunluğun artması ve porların kapanması için önemlidir. Kompozisyonlarda kullanılan feldispatın türü ve miktarı camsı fazın oluşum sıcaklığı ve viskozitesini belirlemektedir. Sistemde $\mathrm{M}_{2} \mathrm{O}$ grubu oksitler ötektik kompozisyonların oluşmasını sağlayarak ergitici görevi görmekte olup, çoğunlukla sodyum ve potasyum feldispattan sağlanmaktadır. $\mathrm{Li}_{2} \mathrm{O}$ 'in porselen bünyelere düşük oranda ilavesi de bünyelerde camsı faz oluşumunu destekleyerek sinterleme sıcaklığını düşürmektedir. Şekil 1'de verilen albit-spodumen faz diyagramı incelendiğinde sisteme yapılan $\mathrm{Li}_{2} \mathrm{O}$ ilavesi ile birlikte ötektik sıcaklığın $1045 \pm 10^{\circ} \mathrm{C}$ ye kadar düştüğü ve sıvı faz oluşumunun kolaylaştığı görülmektedir. Alkali oksitlerle aynı grupta yer aralan ve en küçük katı element olan lityum, hareket kabiliyetinin yüksek olmasından dolayı sodyum ve potasyum okside göre çok daha güçlü bir ergiticidir. $\mathrm{Li}_{2} \mathrm{O}$ kaynağı olarak spodumenin kullanıldığı bünyelerde spodumen oranındaki artı̧̧la birlikte bünyelerin su emme değerlerinin belirgin şeklide düştüğü tespit edilmiştir. Bu da spodumen ilavesi ile geliştirilen bünyelerin standart bünyeye göre çok daha iyi sinterlendiğini ve mikroyapıda por eliminasyonu ile toplam porozitenin daha az olduğunu göstermektedir. Bünyelerin sinterlenme davranışında $\mathrm{Li}_{2} \mathrm{O}$ oranının $\mathrm{Na}_{2} \mathrm{O}$ ve $\mathrm{K}_{2} \mathrm{O}$ 'e göre çok daha etkili olduğunu göstermektedir. 


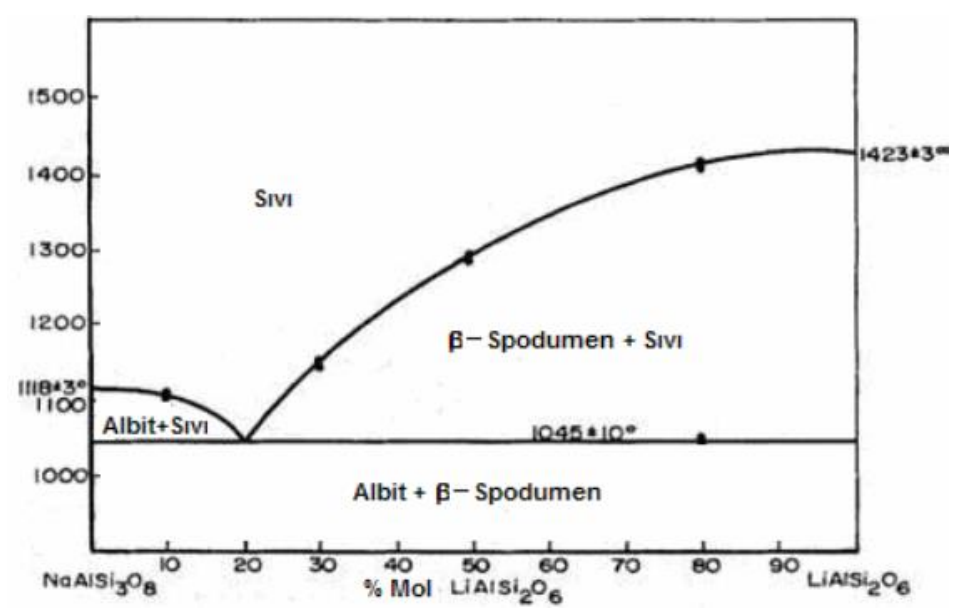

Sekil 1. $\mathrm{NaAlSi}_{3} \mathrm{O}_{8}-\mathrm{LiAlSi}_{2} \mathrm{O}_{6}$ sistemine ait faz diyagramı (Badger ve Hummel 1985).

Bünyelerin kuru mukavemet değerlerinde spodumen ilavesiyle birlikte bir miktar düşüş tespit edilmiştir. Kompozisyon çalışmalarında spodumen standart yüksek alüminalı porselen bünye reçetesi üzerine artan oranlarda ilave edilmiştir. Bu nedenle artan spodumen ilavesi ile birlikte bünyelerde kullanılmakta olan kil ve kaolen oranları da az da olsa azalma göstermektedir. Kuru mukavemet değerlerindeki düşme yönündeki bu eğilimin azalan kil, kaolen oranlarına bağlı olduğu düşünülmektedir.

Bünyelerin pişme mukavemet değerlerinde spodumen ilavesindeki artışla birlikte oldukça belirgin bir artış tespit edilmiştir. Bu durum spodumen kullanımı ile birlikte bünyelerde su emmenin düşmesi, pişme küçülmesinin ve yoğunluğun artması dolayısıyla azalan por boyut ve/veya miktarı ile açıklanabilir. Seramik bünyelerin mikroyapısındaki porozite mukavemete etki eden en önemli parametrelerden biridir. Porların varlığı çatlak başlangıcını kolaylaştırdığından, porozitenin artması ve yoğunluğun azalması ile seramik bünyelerin mukavemeti azalmaktadır (Tarhan 2010, Tarhan ve Tarhan 2019). Seramik bünyelerin kırlma mukavemetini etkileyen bir diğer parametre sinterleme sürecinde mikroyapılarında gelişen müllit kristalleridir. Porselen bünyelerin mukavemeti artan müllit içeriği ile artmaktadır. Çubuksu yapıda olan ikincil müllit kristalleri birincil müllitlere göre bünye mukavemetini daha çok artırır. İkincil müllit kristalleri kil yüzeyinden viskozitesi daha düşük olan amorf faz içine doğru büyümeye başlar. Dolayısıyla amorf fazın viskozitesi düştükçe ikincil müllit kristal boyutları da artış gösterir. Bünyelerde spodumenin varlığı düşük viskoziteli amorf faz gelişimini destekleyerek boyutları daha büyük olan iğnemsi müllit kristallerinin oluşumuna ve bünye mekanik özelliklerinin iyileşmesine neden olmaktadır (Tarhan ve ark. 2017).

Tablo 4. Alümina porselen bünyelerin fiziksel özellikleri

\begin{tabular}{|c|c|c|c|c|}
\hline & STD & SP2 & SP5 & SP10 \\
\hline Pişme Küçülme (\%) & 10,74 & 11,00 & 11,60 & 12,02 \\
\hline Su emme $(\%)$ & 3,90 & 1,96 & 0,14 & 0,00 \\
\hline Kuru Mukavemet $\left(\mathrm{kg} / \mathrm{cm}^{2}\right)$ & 18,5 & 16,4 & 17,9 & 15,6 \\
\hline Pişme Mukavemeti $\left(\mathbf{k g} / \mathrm{cm}^{2}\right)$ & 599,0 & 594,2 & 628,3 & 822,9 \\
\hline Pişme Deformasyonu (mm) & 22 & 25 & 30 & 36 \\
\hline $\begin{array}{l}\text { Isıl Genleşme Katsayısı } \\
\left(10^{-7} \mathbf{C}^{-1}\right)\left(20-400^{\circ} \mathrm{C}\right)\end{array}$ & 60,11 & 60,82 & 61,51 & 61,36 \\
\hline
\end{tabular}

Bünyelere ait deformasyon değerleri Tablo 4'te verilmiştir. Bünyelerde spodumen kullanımı ile birlikte deformasyon değerlerindeki artı̧̧ dikkat çekmektedir. Piroplastik deformasyon, bünyelere herhangi bir yük uygulamadan yalnız sıcaklığın etkisi ile bünyenin kendi ağırlığı altında deforme olma eğilimi olarak tanımlanmaktadır. Sinterleme sürecinde gelişen camsı fazın miktarı ve viskozitesi bünyelerin deformasyon davranışını belirlemektedir. Camsı fazın miktarındaki artış ve viskozitesinin düşmesi ile birlikte porselen bünyelerin deformasyon davranışı kötüleşmektedir (Hopa ve Özel 2016, Güngör 2018, Kunduracı ve ark. 2019, Tarhan ve Tarhan 2019). Spodumen içeren porselen bünyelerde gelişen camsı fazın viskozitesi standart bünyeye göre çok daha düşüktür. Bundan dolayı porselen bünyelerde spodumen kullanımı deformasyon açısından dezavantajlıdır. 
Bünyelerin $400^{\circ} \mathrm{C}^{\prime}$ deki 1 sıl genleşme katsayıları Tablo 4 'te verilmiş olup, spodumen kullanımı ile birlikte porselen bünyenin 1 sıl genleşme katsayısının bir miktar artış gösterdiği görülmektedir. Spodumen bünyelerde direk standart bünye reçetesi üzerine ilave edilerek kullanılmıştır. Bundan dolayı bünyelerde 1sıl genleşme katsayısı düşük olan, az miktarda kuvars fazı içeren kil, kaolen gibi hammaddelerin oranları da bir miktar azalırken, spodumen hammaddesinden sisteme önemli miktarda kuvars $\left(\mathrm{SiO}_{2}\right)$ girmektedir. Tablo 2'de verilen bünyelerin kimyasal analizlerinde de spodumen ilavesi ile birlikte artan $\mathrm{SiO}_{2}$ oranı görülmektedir. Porselen bünyelerde sinterleme sonrasında önemli bir miktar kuvars kalıntı olarak mikroyapıda yer almaktadır. Kristal yapıdaki bu kuvarsın ısıl genleşme katsayısı oldukça yüksek olup bünyelerin ısıl genleşme katsayısını yükseltmektedir. Bu nedenle bünyelerde artan spodumen ilavesi ile birlikte 1 sıl genleşme katsayısının bir miktar arttı̆̆ı düşünülmektedir (Kingery et al. 1976, Eppler and Eppler 2000, Tarhan 2019).

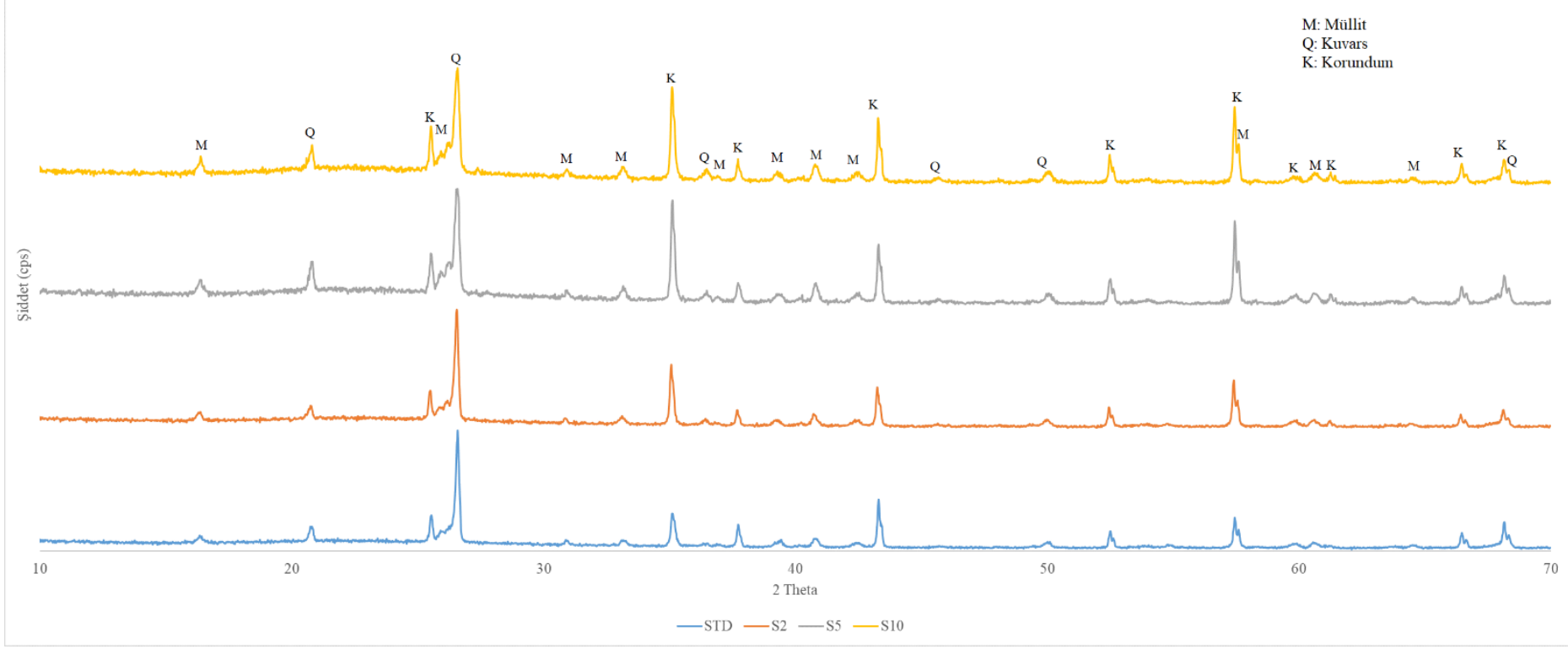

Sekil 2. Hazırlanan kompozisyonların XRD analizlerine ait grafikler.

Bünyelere ait XRD analizi sonucu Şekil 2'de, standart bünye ve en fazla miktarda spodumenin kullanıldığı SP10 kodlu bünyenin SEM mikroyapı görüntüleri Şekil 3'de verilmiştir. Analiz sonuçlarına göre kuvars, müllit ve korund fazları tüm bünyelerde tespit edilmiştir. Ancak yüksek alüminalı porselen bünyelere spodumen ilavesi ile birlikte müllit ve korund fazına ait pik şiddetinin arttığı tespit edilmiştir. Porselen bünyelerde iki farklı tür müllit gelişimi söz konusudur. Birincil müllitin oluşunu metakaolenden oluşan spinel fazın dönümü ile gerçekleşirken ikincil müllitler yaklaşık $1200^{\circ} \mathrm{C}$ sıcaklıklarda kil ve feldispat eriyiği arasındaki reaksiyondan oluşur. Alümina porselenlerde ise üçüncül bir müllit oluşumu gerçekleşir. Bu üçüncü tip müllit korund kristallerinin kenarlarında alüminanın $\mathrm{SiO}_{2}$ bakımından zengin matris içinde çözünmesi ve daha fazla çökeltilmesiyle gelişir (Montoya ve ark. 2010) Yapılan çalışmada alümina porselen bünyesine spodumen ilavesi ile birlikte müllit fazındaki artışla birlikte korund fazındaki artış dikkati çekmektedir. $\mathrm{Bu}$ da bünyede müllit gelişiminin korund kristallerinden çok kil ve feldispat eriyiği arasındaki reaksiyonla gerçekleştiğini göstermektedir. Spodumenin amorf faz gelişimini artırması ve viskozitesini düşürmesi müllit kristallerinin kil minerallerinden eriyiğe doğru gelişimini kolaylaştırmıştır. 

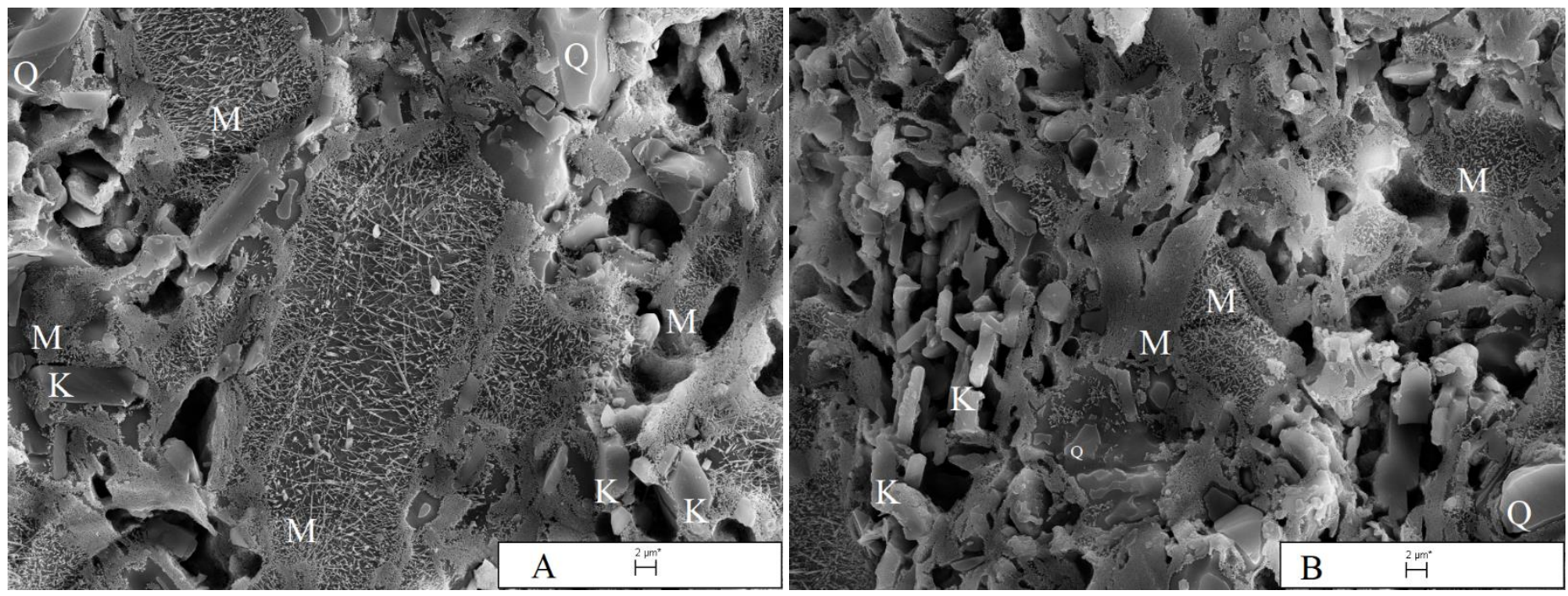

Şekil 3. Dağlanmış ikincil elektron SEM görüntüleri A) SP10, B) STD kodlu kompozisyonlar(Q: kuvars, K: korund, M: müllit)

\section{Genel Sonuçlar}

Bu çalışmada, yüksek oranda alümina içeren porselen bünye kompozisyonlarında spodumen kullanımının bünyelerin fiziksel, 1sı1, mekanik ve mikroyapı özelliklerine etkileri araştıılarak bünyelerde kullanılabilirliği incelenmiştir. Bünyelerde spodumen kullanımı bünyelerin sinterlenmesini kolaylaştırarak bünyelerin su emmesini düşürmüş ve pişme küçülmesini artırmıştır. Bünyelerde artan sinterleme oranına paralel olarak porozitede azalmıştır. Bununla birlikte bünyelerde artan müllit faz gelişimi ve artan korund faz miktarı bünyelerin mekanik özelliklerini olumlu yönde etkileyerek pişmiş mukavemet değerlerinin belirgin şekilde artmasına neden olmuştur. Ancak spodumen kullanımı ile bünyelerin sinterleme davranışındaki gelişmeye de bağlı olarak bünyelerin deformasyon değerleri önemli ölçüde artmıştır. Ayrıca geliştirilen bünyelerde spodumen kullanımı bünyenin 1sıl genleşme katsayısını bir miktar arttırmıştır. Yapılan çalışma sonucunda elde edilen tüm sonuçlar değerlendirildiğinde; yüksek alümina içeren porselen bünyelerde spodumen kullanımı bünyelerde sinterlemeyi hızlandırdığından teknik özellikler ve mikroyapı kontrollü olarak pişirim rejimi üzerinde pişme sıcaklıklarının düşürülmesi ve/veya pişirim sürelerinin kısaltılması yönünde çalışmaların yapılabileceği ve bünye kompozisyonu üzerinde yapılacak optimizasyon çalışmaları ile spodumenin yüksek alüminalı porselen bünyelerde kullanılabileceği sonucuna varılmıştır.

\section{Kaynaklar}

Badger, W.B. ve Hummel F.A. (1985), Phase equilibrium in system $\mathrm{LiAlSiO}_{4}-\mathrm{NaAlSiO}_{4}-\mathrm{SiO}_{2}$, J. Am. Ceram. Soc., 68[2], C-46-C47

Bragança, S. R., Lengler, H. C. M., \& Bergmann, C. P. (2011). Spodumene-bearing rock as flux for triaxial ceramic bodies. Advances in Applied Ceramics, 110(5), 293-300

Bragança, S. R., Lengler, H. C. M., \& Bergmann, C. P. (2012). Wollastonite as a flux for ceramics bodies. In Materials Science Forum (Vol. 727, pp. 1016-1021). Trans Tech Publications Ltd.

Brasileiro, C. T., Conte, S., Contartesi, F., Melchiades, F. G., Zanelli, C., Dondi, M., \& Boschi, A. O. (2021). Effect of strong mineral fluxes on sintering of porcelain stoneware tiles. Journal of the European Ceramic Society, 41(11), 5755-5767

Carty, W. M., \& Senapati, U. (1998). Porcelain — raw materials, processing, phase evolution, and mechanical behavior. Journal of the American Ceramic Society, 81(1), 3-20

Carús, L. A., de Souza, F., \& Bragança, S. R. (2012). Use of wollastonite as a flux for bone china bodies. International Scholarly Research Notices 
Ceylan, A., Ebeoğlugil, M.F., Küçük, A. (2005), Farklı tür feldispat ilavelerinin yer karosu bünyesine etkilerinin incelenmesi, Seramik Türkiye, No.7, 131-137

Elmaghraby, M.S., Ismail, A.I.M., Ghabrial, D.S., \& Abd El-Shakour Z. A. (2020). Effect of Nepheline Syenite Additives on the Technological Behavior of Ceramics and Porcelain Stoneware Tiles. Silicon 12, 1125-1136

Eppler, R. A.and Eppler, D. R., 2000. Glazes and glass coatings, American Ceramic Society, Westerville, Ohio

Esposito, L., Salem, A., Tucci, A., Gualtieri, A., Jazayeri, S.H. (2005), The use of nepheline-syenite n a body bix for porcelain stoneware tiles, Ceramics International, 31, 233-240

Güngör, F. (2018). Investigation of pyroplastic deformation of whitewares: Effect of crystal phases in the ' $\mathrm{CaO}$ 'based glassy matrix. Ceramics International, 44(11), 13360-13366

Güngör, F., \& Ay, N. (2018). The effect of particle size of body components on the processing parameters of semi-transparent porcelain. Ceramics International, 44(9), 10611-10620

Hopa, D. Y. T., \& Emel, Ö. Z. E. L. (2016). Kaolen türünün sağlik gereçleri porselen bünyesinin piroplastik deformasyonu üzerine etkisi. Gazi Üniversitesi Mühendislik Mimarlık Fakültesi Dergisi, 31(2)

Iqbal, Y. ve Lee, W.E. (1999), Fired porcelain microstructures revisited, J. Am. Ceram. Soc., 82 (121), 3584-3590

Iqbal, Y., Messer, P.F., Lee, W.E. (2000), Microstructural evolution in triaxial porcelain, J. Am. Ceram. Soc. 83 (12), 3121-3127

Ke, S., Cheng, X., Wang, Y., Wang, Q., \& Wang, H. (2013). Dolomite, wollastonite, and calcite as different CaO sources in anorthitebased porcelain. Ceramics International, 39(5), 4953-4960

Kingery WD, Bowen HK, Uhlmann DR, Introduction to Ceramics. USA: John Wiley and Sons Inc; ISBN 0-471-47860-1. 1960. pp 809

Kivitz, E., Palm, B., Heinrich, J. G., Blumm, J., \& Kolb, G. (2009). Reduction of the porcelain firing temperature by preparation of the raw materials. Journal of the European Ceramic Society, 29(13), 2691-2696

Kundurac1, N. \& Aydın, T. (2015). The effect of nepheline syenite addition on sanitaryware Body, International Journal of Engineering Research and Development, 7 (2), 16-19. DOI: 10.29137/umagd.346107

Kunduracı, N., Tarhan, B., \& Sarısakal, C. (2019). Seramik Sağlık Gereçleri Ürünlerinde Piroplastik Deformasyonun Azaltılmasına Bağlı Olarak Geliştirilen Kompozisyonların Üretim Maliyeti Açısından Değerlendirilmesi. International Journal of Engineering Research and Development, 11(2), 474-480

Kurama, S., \& Ozel, E. (2009). The influence of different $\mathrm{CaO}$ source in the production of anorthite ceramics. Ceramics International, 35(2), 827-830

Lee, W. E., \& Iqbal, Y. (2001). Influence of mixing on mullite formation in porcelain. Journal of the European Ceramic Society, 21(14), 2583-2586

Lerdprom, W., Chinnam, R. K., Jayaseelan, D. D., \& Lee, W. E. (2016). Porcelain production by direct sintering. Journal of the European Ceramic Society, 36(16), 4319-4325

Lu, H.Y., Wang, W.L., Tuan, W.H., Lin, M.H. (2004), Acicular mullite in vitrified kaolin, J. Am. Ceram. Soc., 87 (10), 1843-1847

Montoya, N., Serrano, F. J., Reventós, M. M., Amigo, J. M., \& Alarcón, J. (2010). Effect of $\mathrm{TiO}_{2}$ on the mullite formation and mechanical properties of alumina porcelain. Journal of the European Ceramic Society, 30(4), 839-846 
Tarhan, B. (2019). Usage of fired wall tile wastes into fireclay sanitaryware products. Journal of the Australian Ceramic Society, 55(3), 737-746

Tarhan, B., \& Tarhan, M. (2019). Çanakkale bölgesi alkali kaynağının seramik sağlık gereçleri bünyesi ısıl ve mikroyapı özellikleri üzerine etkisi. Dicle Üniversitesi Mühendislik Fakültesi Mühendislik Dergisi, 10(2), 675-687

Tarhan, B., \& Tarhan, M. (2021). Utilization of perlite as an alternative raw material in the production of ceramic sanitaryware. Journal of Thermal Analysis and Calorimetry, 1-10

Tarhan, B., Tarhan, M., \& Aydin, T. (2017). Reusing sanitaryware waste products in glazed porcelain tile production. Ceramics International, 43(3), 3107-3112

Tarhan, M, 2010. Porselen karo bünyelerinde sinterleme hızı-kompozisyon ilişkileri. Doktora Tezi, Anadolu Üniversitesi Fen Bilimleri Enstitüsü, Eskişehir, 230

Tarhan, M., \& Tarhan, Ş. B. (2019). Sırlı Porselen Karo Üretimi için Alternatif Hammadde Olarak Eşme/Uşak Feldspatı. Afyon Kocatepe Üniversitesi Fen ve Mühendislik Bilimleri Dergisi, 19(2), 429-438

Tucci, A., Esposito, L., Malmusi, L., Rambaldi, E. (2007), New body mixes for porcelain stoneware tiles with improved mechanical characteristics, Journal of The European Ceramic Society, 27, 1875-1881

Turkmen, O., Kucuk, A., \& Akpinar, S. (2015). Effect of wollastonite addition on sintering of hard porcelain. Ceramics International, 41(4), 5505-5512 